Société d'histoire de la révolution de 1848 et des

révolutions du XIXe siècle

43 | 2011

L'ordre électoral : savoirs et pratiques

\title{
Roger DUPUY, La Garde nationale, 1789-1872, collection Folio Histoire, Paris, Gallimard, 2010, 606 p. ISBN : 978-2-07-034716-2. 11 euros.
}

\section{Aurélien Lignereux}

\section{OpenEdition}

\section{Journals}

Édition électronique

URL : http://journals.openedition.org/rh19/4176

DOI : $10.4000 /$ rh 19.4176

ISSN : $1777-5329$

Éditeur

La Société de 1848

Édition imprimée

Date de publication : 13 novembre 2011

Pagination : 159-161

ISSN : 1265-1354

\section{Référence électronique}

Aurélien Lignereux, «Roger DUPUY, La Garde nationale, 1789-1872, collection Folio Histoire, Paris,

Gallimard, 2010, 606 p. ISBN : 978-2-07-034716-2. 11 euros. », Revue d'histoire du XIXe siècle [En ligne], 43 | 2011, mis en ligne le 13 juillet 2012, consulté le 22 septembre 2020. URL : http:// journals.openedition.org/rh19/4176 ; DOI : https://doi.org/10.4000/rh19.4176

Ce document a été généré automatiquement le 22 septembre 2020

Tous droits réservés 


\title{
Roger DUPUY, La Garde nationale, 1789-1872, collection Folio Histoire, Paris, Gallimard, 2010, 606 p. ISBN : 978-2-07-034716-2. 11 euros.
}

\author{
Aurélien Lignereux
}

Par cette histoire de la Garde nationale durant ses huit décennies d'existence, Roger Dupuy opère un retour magistral sur l'institution qui lui avait servi, il y a quarante ans, de sujet de thèse de $3^{e}$ cycle, et à laquelle son œuvre est restée attachée, qu'il s'agisse d'identifier les formes de mobilisation populaire, d'étudier les adversaires des gardes nationaux que furent les chouans, ou d'organiser le premier colloque dédié à la Garde nationale ${ }^{1}$. C'est dire la maturité, et partant l'autorité, du présent ouvrage. Un tel investissement se comprend au vu des enjeux que porte ce corps au siècle des révolutions : la Garde nationale est au cœur des débats relatifs à la force publique, à la citoyenneté, au droit à l'insurrection et aux mises en scène de l'unanimisme, à l'hégémonie de Paris et de ses classes moyennes sur la France du XIX siècle. Cruciale et controversée, la Garde nationale a suscité un "patchwork» d'images (p.12), admiratives à l'égard de l'idéal de nation armée et d'unité du peuple qu'elle incarnerait ou hostiles envers cette milice bourgeoise. Optant résolument pour une trame chronologique, Roger Dupuy suit les tensions d'un corps -d'emblée voué à se tenir sur la corde raide de l'équilibre car chargé à la fois de prévenir tout risque de réaction et de contenir les excès populaires. L'exercice est si périlleux qu'il conduit des gardes nationaux à se retrouver face à face, de part et d'autre des barricades de juin 1848 . Cette approche, qui souligne le modérantisme de la Garde nationale en dépit de la tendance à la radicalisation de la petite bourgeoisie, rénove la connaissance de certaines grandes journées (14 Juillet, 9 Thermidor) et personnalités (La Fayette), mais l'élégance de la narration se fait au sacrifice de l'appareil statistique et cartographique que l'on était en droit d'attendre. 
2 On serait même tenté de pasticher les mots de Jacques Rougerie à propos de la Commune - trop fugitivement évoquée : ce livre fait davantage figure de crépuscule d'une manière d'écrire l'histoire de la Garde nationale à laquelle se rattachent Louis Girard et Georges Carrot, que d'aurore historiographique. Est en cause la distorsion chronologique : la période 1789-1795 se taille la part du lion avec dix chapitres, contre six pour les 77 années suivantes! Voilà qui évite, il est vrai, toute redondance pour la monarchie de Juillet et la Seconde République, désormais bien connues grâce à Mathilde Larrère et Louis Hincker ${ }^{2}$. En revanche, la période napoléonienne reste focalisée sur les aspects militaires, au détriment de pistes émergentes ${ }^{3}$, et la Restauration est réduite au rang d'intermède, sans égard pour l'essai de réinvention de la Garde nationale de 1814 à 1818. Les débats ne se sont pas bornés au commandement confié au comte d'Artois ni aux difficultés matérielles : la situation dans l'Ouest que connaît par ailleurs si intimement Roger Dupuy suggère qu'il s'agit rien de moins que d'une tentative de mettre fin à la Révolution. L'appellation de garde nationale est parfois mise en cause ; surtout, les autorités s'interrogent sur la meilleure façon de reconvertir l'organisation militaire des paroisses réactivée par l'insurrection de 1815 : faut-il officialiser cette force spontanée pour mieux l'utiliser et d'abord la contrôler ou bien le risque de la pérenniser et de réactiver les clivages entre communes est-il trop élevé? C'est annoncer un second regret, celui d'un terrain d'enquête réduit à Paris. Sans même parler de l'absence de comparaison internationale, à rebours de la manière dont s'écrit désormais l'histoire des institutions, ce choix est paradoxal vu que ce livre entend évaluer le rapport de forces et le jeu des représentations entre Paris et la province. Le silence sur les villes et sur les bourgs conduit à négliger les attributions ordinaires des gardes, et c'est là une troisième insatisfaction. La Garde nationale est aussi une police civique ; force de proximité, elle constitue une variante originale du policing, et c'est donc l'histoire d'une autre confiscation, celle de la sécurité par des corps spécialisés, qui est passée sous silence. Ajoutons que l'inégale assiduité des gardes en dit long sur le succès ou non d'un modèle de sociabilité locale, martiale et masculine; bref, sur ce "militarisme municipal diffus » entrevu par Maurice Agulhon dans La République au village(p. 453). Mais c'est s'engager dans une démarche anthropologique déclinée par l'auteur, qui préfère assumer « une histoire politique classique préoccupée surtout de se demander si focaliser l'attention sur le rôle joué par la Garde nationale modifie ou non la connaissance que nous avons des épisodes majeurs de cette période » (p. 16). Si cet objectif est parfaitement tenu, d'autres voies mériteraient d'être retenues.

\section{NOTES}

1. . Roger Dupuy, La Garde nationale et les débuts de la Révolution en Ille-et-Vilaine (1789-mars 1793), Paris, Klincksieck, 1972 ; Roger Dupuy, La politique du peuple, XVIII ${ }^{e}-X^{e}$ siècle. Racines, permanences et ambiguïtés du populisme, Paris, A. Michel, 2002; Serge Bianchi et Roger Dupuy [dir.], La Garde nationale entre nation et peuple en armes : mythes et réalités, 1789-1871. Actes du colloque de l'université de Rennes 2, 24-25 mars 2005, Rennes, Presses universitaires de Rennes, 2006. 
2. . Mathilde Larrère, La garde nationale de Paris sous la monarchie de Juillet, Le pouvoir au bout du fusil ?, Thèse d'histoire sous la direction d'Alain Corbin, Université Paris 1, 2000 ; Louis Hincker, Citoyens-combattants à Paris, 1848-1851, Villeneuve-d'Ascq, Presses universitaires du Septentrion, 2007.

3. . John Dunne, "La Garde nationale sous Napoléon ", in Bruno Béthouard [dir.], Napoléon, Boulogne et l'Europe, Boulogne, Cahiers du littoral, 2001, p. 80-87. 